\begin{tabular}{ll|l} 
Case Reports in & \multicolumn{2}{c}{ Case Rep Gastroenterol 2014;8:221-226 } \\
\cline { 2 - 3 } Gastroenterology & $\begin{array}{l}\text { DOI: 10.1159/000364819 } \\
\text { Published online: June 14, 2014 }\end{array}$ & $\begin{array}{l}\text { ○ 2014 S. Karger AG, Basel } \\
1662-0631 / 14 / 0082-0221 \$ 39.50 / 0 \\
\text { www.karger.com/crg }\end{array}$ \\
\cline { 2 - 3 } & $\begin{array}{l}\text { This is an Open Access article licensed under the terms of the Creative Commons } \\
\text { Attribution-NonCommercial 3.0 Unported license (CC BY-NC) (www.karger.com/OA- } \\
\text { license), applicable to the online version of the article only. Distribution permitted for non- } \\
\text { commercial purposes only. }\end{array}$
\end{tabular}
commercial purposes only.

\title{
Duodenal Hemorrhage from Pancreatic Cancer Infiltration Controlled through Combination Therapy with Gemcitabine and S-1
}

\author{
Ryoji Takada ${ }^{a}$ Tatsuya Ioka ${ }^{a}$ Hironari Sueyoshi ${ }^{a}$ Nobuko Ishida $^{a}$ \\ Takuo Yamai $^{a}$ Nobuyasu Fukutake ${ }^{a}$ Reiko Ashida ${ }^{a}$ Hiroyuki Uehara ${ }^{a}$ \\ Akemi Takenaka $^{b}$ Yasuhiko Tomita ${ }^{b}$ Kazuhiro Katayama ${ }^{a}$ \\ Departments of ${ }^{a}$ Hepatobiliary and Pancreatic Oncology and ${ }^{b}$ Pathology, Osaka Medical \\ Center for Cancer and Cardiovascular Diseases, Osaka, Japan
}

\section{Key Words}

Pancreatic cancer · Duodenal infiltration · Chemotherapy · Gastrointestinal bleeding

\begin{abstract}
$2.6 \%$ of pancreatic cancer patients have the primary manifestation of gastrointestinal bleeding. It is not feasible to stop the duodenal hemorrhage caused by the pancreatic cancer infiltration. A 43-year-old woman who was diagnosed as having pancreatic cancer with multiple hepatic metastases and duodenal infiltration was administered gemcitabine and S-1 combination therapy. During the chemotherapy, initially, bleeding occurred due to duodenal infiltration. However, we continued the chemotherapy and duodenal infiltration was markedly reduced in size and did not rebleed. Aggressive chemotherapy contributed to maintenance of performance status as well as improvement of quality of life for the patient.
\end{abstract}

(C) 2014 S. Karger AG, Basel

\section{Introduction}

Pancreatic cancer causes many digestive symptoms such as abdominal pain, jaundice, nausea, vomiting, hematemesis, melena and so on, by its direct infiltration into the surrounding organs which include the bile duct, duodenum, stomach, jejunum and colon. It is very important for us to manage these symptoms successfully due to their life-threatening nature. Of these symptoms, duodenal bleeding is one of the most difficult to control. 
Takada et al.: Duodenal Hemorrhage from Pancreatic Cancer Infiltration Controlled through Combination Therapy with Gemcitabine and S-1

$35.7 \%$ of all pancreatic cancer patients suffer from duodenal infiltration [1], and $2.6 \%$ of pancreatic cancer patients have the primary manifestation of gastrointestinal bleeding [2]. Although pancreatic cancer is a rare cause of upper gastrointestinal bleeding, it is not feasible to stop that because of the pancreatic cancer infiltration. Failure of hemostasis results in a poor prognosis. Massive hemorrhaging might lead to an oncological emergency. In general, hemostatic methods for duodenal hemorrhaging include endoscopic hemostasis, transcatheter arterial embolization and/or surgery.

Here we report an effective hemostatic case of duodenal bleeding caused by direct infiltration of the pancreatic cancer, through aggressive chemotherapy. This chemotherapy contributed to the maintenance of performance status as well as improved quality of life for the patient. We believe that chemotherapy can be another effective method of hemostasis. However, there have been no official reports about the effectiveness of chemotherapy as a method of hemostasis thus far.

\section{Case Report}

A 43-year-old woman was admitted to a clinic with right hypochondriac pain in April 2012. Upper gastrointestinal endoscopy was performed and detected no abnormalities. Her symptom continued with weight loss. Abdominal ultrasonography was performed and found a pancreatic cancer. She was admitted to our hospital in October 2012. Computed tomography (CT) showed a pancreatic head cancer with multiple hepatic metastases. It also revealed irregular duodenal stenosis, suggesting direct cancer infiltration into the second portion of the duodenum (fig. 1). Percutaneous needle aspiration was performed to the pancreatic tumor. The pathological diagnosis was adenocarcinoma (fig. 2). Laboratory findings on admission showed mild anemia and coagulation abnormalities. Tumor markers were markedly elevated (table 1); CA19-9 was extremely high $(>100,000 \mathrm{U} / \mathrm{ml})$.

The patient's prognosis was considered extremely poor. Comparison of the CT findings on admission with those at the primary clinic 2 weeks previously demonstrated rapid tumor progression; the hepatic metastases had increased in size by approximately $15 \%$. We concluded that we might have no chance to treat her with second-line chemotherapy if first-line chemotherapy failed. Therefore, we selected combination therapy with gemcitabine and S-1 (GS therapy), currently the therapy with the highest antitumor effect in Japan.

Melena occurred just before the initiation of chemotherapy. Subsequent upper gastrointestinal endoscopy was performed and revealed a giant ulcer $3 \mathrm{~cm}$ in diameter with oozing. We found neither arterial hemorrhage nor exposed blood vessels (fig. 3). Her anemia did not deteriorate without any endoscopic hemostatic procedure and she was eligible for the scheduled chemotherapy. Melena occurred again on day 5 of chemotherapy with progressive anemia from 9.5 to $7.2 \mathrm{~g} / \mathrm{dl}$. Gastrointestinal endoscopy could not be performed because she rejected it. Total parenteral nutrition was started with a blood transfusion of 4 units of packed red blood cells. We presented the treatment option including gastrointestinal bypass surgery to her, but she selected to continue chemotherapy. The anemia did not worsen after all and a liquid diet was started on day 20. She showed no adverse events of grade 2 or greater severity, such as thrombocytopenia or neutropenia, according to CTCAE v4. She was discharged with a low risk of rebleeding on day 38.

GS therapy was continued after discharge. CT was performed at month 2 and showed that the primary lesion and the hepatic metastases had been reduced, meeting the criteria for a partial response (RECIST v1.1). The CT findings at month 6 showed re-enlargement of the primary lesion, an increase in the number and size of hepatic metastases and the ap- 
Takada et al.: Duodenal Hemorrhage from Pancreatic Cancer Infiltration Controlled through Combination Therapy with Gemcitabine and S-1

pearance of ascites. The patient took best supportive care. She died 7.5 months after the initiation of therapy.

The patient's course after admission is presented in supplementary figure 1 (see www.karger.com/doi/10.1159/000364819).

\section{Discussion}

Pancreatic cancer can be associated with gastrointestinal bleeding. The hemorrhagic causes are divided into three categories: rupture of esophageal or gastric varices secondary to obstruction of the splenic or portal vein, tumor hemorrhage from the pancreatic duct orifice (hemosuccus or wirsungorrhage), and bleeding due to direct infiltration of the tumor into the stomach or duodenum [3]. Lee et al. [2] reported that $2.6 \%$ of pancreatic cancer patients initially presented the symptom of gastrointestinal bleeding.

Duodenal infiltration of pancreatic cancer occurred in $35.7 \%$ of all patients [1]. Duodenal infiltration often causes not only bleeding but also duodenal obstruction. Some researchers reported that pancreatic tumors usually have the character of the infiltrative growth, but seldom cause bleeding because of their ischemic nature [4]. On the other hand, once bleeding has occurred, it often recurs, resulting in serious massive blood loss [5-7].

In cases with bleeding due to duodenal infiltration, endoscopic hemostasis, transcatheter arterial embolization or surgical hemostasis is performed. Endoscopic hemostasis is effective to the exposed blood vessels [8]. The procedure might be highly difficult when the tumor infiltration makes the duodenal lumen narrow as this disturbs the appropriate endoscopic view and the maneuver. Moreover, the fragile tumor tissue might impede endoscopic hemostasis with clipping or focal injection of hypertonic saline epinephrine. Hemorrhagic recurrence might often occur after temporary hemostasis [7]. Transcatheter arterial embolization is useful for temporary hemostasis in cases with arterial bleeding [9], but it is not indicated for venous bleeding as in our case. Surgical hemostasis includes pancreaticoduodenectomy, the resection of the entire bleeding area and gastrointestinal bypass surgery. Pancreaticoduodenectomy is extremely invasive for patients with highly advanced disease with hepatic metastases. It probably does not improve the prognosis [7]. For these patients, gastrointestinal bypass surgery might be optimal. However, if the pancreatic cancer progresses before the patient's general condition after gastrointestinal bypass surgery recovers, we cannot perform the chemotherapy.

In our case, the CT findings showed rapid tumor growth within 2 weeks. Cases with markedly elevated CA19-9 and metastatic foci in both hepatic lobes have extremely poor outcomes [10]. These findings suggested her prognosis would be poor. The GEST study that was carried out in Japan and Taiwan demonstrated no better usefulness of GS therapy in comparison with gemcitabine monotherapy in terms of overall survival [11]. From this point of view, GS therapy was not regarded as a standard treatment (GS vs. gemcitabine monotherapy: median overall survival 9.4 vs. 8.3 months; hazard ratio 0.93 ), though the response rate was significantly better for GS therapy than for gemcitabine monotherapy (GS vs. gemcitabine monotherapy: overall response rate 29.3 vs. $13.3 \%, p<0.01$ ). GS therapy might be indicated for cases with highly advanced disease as ours. In spite of the higher frequency of hematologic toxicity than that with gemcitabine monotherapy, the rate of thrombocytopenia of grade 3 or greater severity, the risk factor of bleeding, was only $17.2 \%$ in the GEST study. It was considered that the high antitumor efficacy of GS therapy was worth the risk of bleeding. As a result, GS therapy with an acceptable response in this patient accomplished 
Takada et al.: Duodenal Hemorrhage from Pancreatic Cancer Infiltration Controlled through Combination Therapy with Gemcitabine and S-1

reduction of the duodenal infiltration. Thrombocytopenia, the adverse effect, might cause fetal bleeding.

In our case, the patient's performance status and bone marrow function were good, the ulcer from duodenal infiltration was shallow and the bleeding was venous. These reasons contributed to the success of the hemostasis. Furthermore, she had a strong will to live due to her children. After all options had been fully explained, she selected to give priority to ameliorating the pancreatic cancer with chemotherapy without solid food intake to reduce the risk of bleeding.

We did not find any reports that reduction of pancreatic cancer by chemotherapy achieved hemostasis of bleeding caused by tumor infiltration. Our therapeutic choice was not considered to be standard from the viewpoint of reliability, but since the examination results revealed the patient's expected survival period was very limited and the merits of therapy were more than the risks, we suggested chemotherapy as a choice. Prior to the therapy, we obtained fully informed consent from the patient. During the procedure, we closely observed her condition.

In conclusion, aggressive chemotherapy reduced the duodenal infiltration of pancreatic cancer to achieve hemostasis. It contributed to maintenance of the patient's performance status as well as to improvement of her quality of life.

\section{Acknowledgement}

The authors wish to personally thank George Hamilton for his writing assistance in creating this paper.

\section{References}

1 Tanaka M: Pancreatic Cancer Registry Report 2007 (in Japanese). Suizou 2007;22:e86-e88.

2 Lee P, Sutherland D, Feller ER: Massive gastrointestinal bleeding as the initial manifestation of pancreatic carcinoma. Int J Pancreatol 1994;15:223-227.

3 Lin YH, Chen CY, Chen CP, et al: Hematemesis as the initial complication of pancreatic adenocarcinoma directly invading the duodenum: a case report. World J Gastroenterol 2005;11:767-769.

4 Mizukami Y, Arisato S, Satou K, et al: A case of anaplastic carcinoma of the pancreas, disclosed a hemosuccus pancreaticus (in Japanese). Nihon Shokakibyo Gakkai Zasshi 1997;94:706-711.

5 Hirai R, Negoro Y, Hyodo T, et al: Hematemesis as the initial manifestation of pancreatic cancer directly invading the duodenum: a case report. Suizou 2008;23:172-179.

6 Sunose Y, Hirai K, Yoshinari D, et al: Case report: A case of pancreatic cancer invading the duodenum with an initial manifestation of hypovolemic shock from duodenal bleeding. Nihon Fukubu Kyukyu Igakkai Zasshi 2010;31:119-122.

-7 Tomita H, Osada S, Matsuo M, et al: Pancreatic cancer presenting with hematemesis from directly invading the duodenum: report of an unusual manifestation and review. Am Surg 2006;4:363-366.

8 Sakamoto N, Onozato Y, Iizuka H, et al: Study of 11 cases which were performed endoscopic hemostasis for bleeding from the second portion of duodenum (in Japanese). Prog Dig Endosc 2005;66:26-30.

9 Kono Y, Katayama N, Morita H, et al: Transcatheter embolization for massive hemorrhage from the duodenum secondary to malignant tumors (in Japanese). Rinshou Houshasen 2004;49:1826-1830.

-10 Saad ED, Machado MC, Wajsbrot D, et al: Pretreatment CA 19-9 level as a prognostic factor in patients with advanced pancreatic cancer treated with gemcitabine. Int J Gastrointest Cancer 2002;32:35-41.

-11 Ueno H, Ioka T, Ikeda M, et al: Randomized phase III study of gemcitabine plus S-1, S-1 alone, or gemcitabine alone in patients with locally advanced and metastatic pancreatic cancer in Japan and Taiwan: GEST study. J Clin Oncol 2013;31:1640-1648. 
Takada et al.: Duodenal Hemorrhage from Pancreatic Cancer Infiltration Controlled through Combination Therapy with Gemcitabine and S-1

Table 1. Laboratory findings on admission

\begin{tabular}{|c|c|c|c|c|c|}
\hline \multicolumn{3}{|l|}{ Blood counts } & \multicolumn{3}{|c|}{ Biochemistry } \\
\hline WBC & $8.46 \times 10^{3} / \mu \mathrm{l}$ & $\left(3.5-9.9 \times 10^{3}\right)$ & $\mathrm{TP}$ & $6.8 \mathrm{~g} / \mathrm{dl}$ & $(6.7-8.3)$ \\
\hline $\mathrm{RBC}$ & $338 \times 10^{4} / \mu \mathrm{l}$ & $\left(400-500 \times 10^{4}\right)$ & Alb & $4.0 \mathrm{~g} / \mathrm{dl}$ & $(3.9-4.9)$ \\
\hline $\mathrm{Hb}$ & $10.2 \mathrm{~g} / \mathrm{dl}$ & $(13.0-16.0)$ & T-bil & $0.4 \mathrm{~g} / \mathrm{dl}$ & $(0.2-1.2)$ \\
\hline $\mathrm{Ht}$ & $30.5 \%$ & $(40-55)$ & AST & $50 \mathrm{IU} / \mathrm{l}$ & $(13-33)$ \\
\hline Plt & $48.2 \times 10^{4} / \mu \mathrm{l}$ & $\left(12-38 \times 10^{4}\right)$ & ALT & $66 \mathrm{IU} / \mathrm{l}$ & $(8-42)$ \\
\hline \multicolumn{3}{|l|}{ Hemostasis } & ALP & $550 \mathrm{IU} / \mathrm{l}$ & (115-359) \\
\hline РT\% & $81 \%$ & $(70-130)$ & $\gamma \mathrm{GTP}$ & $90 \mathrm{IU} / \mathrm{l}$ & $(6-58)$ \\
\hline PT-INR & 1.07 & $(0.85-1.2)$ & AMY & $45 \mathrm{IU} / \mathrm{l}$ & $(33-120)$ \\
\hline FDP & $9.5 \mu \mathrm{g} / \mathrm{ml}$ & $(<5.0)$ & LDH & 374 IU/l & (119-229) \\
\hline \multicolumn{3}{|l|}{ Tumor markers } & Dis & $0.44 \mathrm{mg} / \mathrm{dl}$ & $(0.36-1.06)$ \\
\hline CA19-9 & $>100,000 \mathrm{U} / \mathrm{ml}$ & $(\leq 37)$ & $\mathrm{Na}$ & $139 \mathrm{mEq} / \mathrm{l}$ & $(135-151)$ \\
\hline DUPAN-II & $744 \mathrm{U} / \mathrm{ml}$ & $(\leq 150)$ & $\mathrm{K}$ & $3.8 \mathrm{mEq} / \mathrm{l}$ & $(3.5-5.0)$ \\
\hline \multirow[t]{3}{*}{ CEA } & $7.4 \mathrm{ng} / \mathrm{ml}$ & $(\leq 5.0)$ & $\mathrm{Cl}$ & $102 \mathrm{mEq} / \mathrm{l}$ & (98-108) \\
\hline & & & CRP & $1.63 \mathrm{mg} / \mathrm{dl}$ & $(\leq 0.3)$ \\
\hline & & & $\mathrm{HbA1c}$ & $5.7 \%$ & $4.6-6.2$ \\
\hline
\end{tabular}

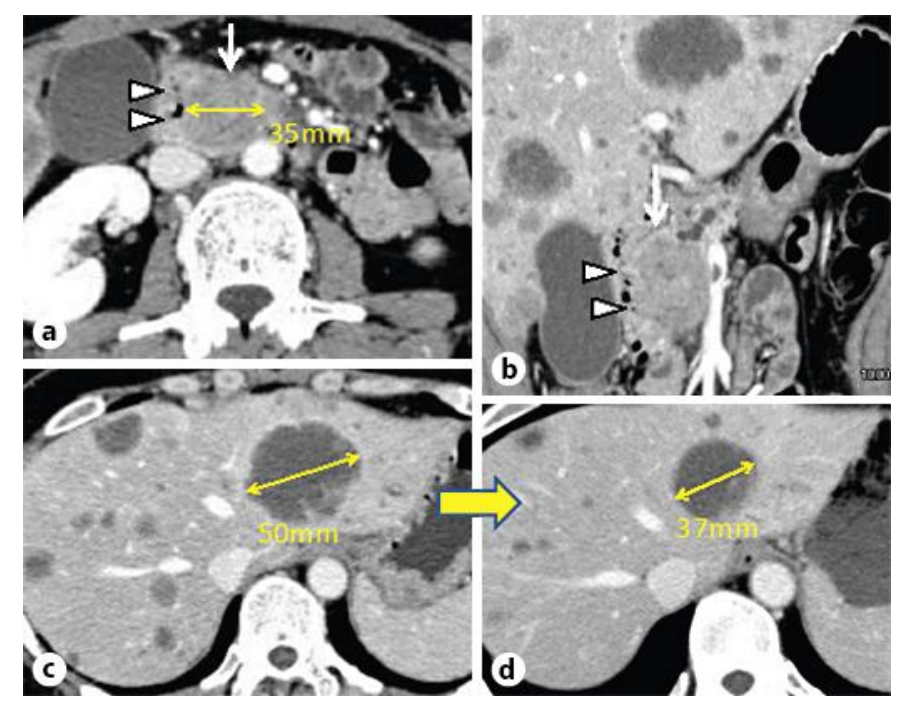

Fig. 1. CT images showed a pancreatic head cancer as an ischemic mass of $35 \mathrm{~mm}$ (arrows), suggesting direct infiltration (arrowheads) into the duodenum, as well as multiple hepatic metastases in both hepatic lobes. a, b On admission. c Before therapy. $\mathbf{d}$ Two months after therapy. 


\begin{tabular}{ll|l} 
Case Reports in & \multicolumn{2}{l}{ Case Rep Gastroenterol 2014;8:221-226 } \\
\cline { 2 - 3 } Gastroenterology & DOI: 10.1159/000364819 & $\begin{array}{l}\text { ○ 2014 S. Karger AG, Basel } \\
\text { www.karger.com/crg }\end{array}$ \\
\cline { 2 - 3 } &
\end{tabular}

Takada et al.: Duodenal Hemorrhage from Pancreatic Cancer Infiltration Controlled through Combination Therapy with Gemcitabine and S-1

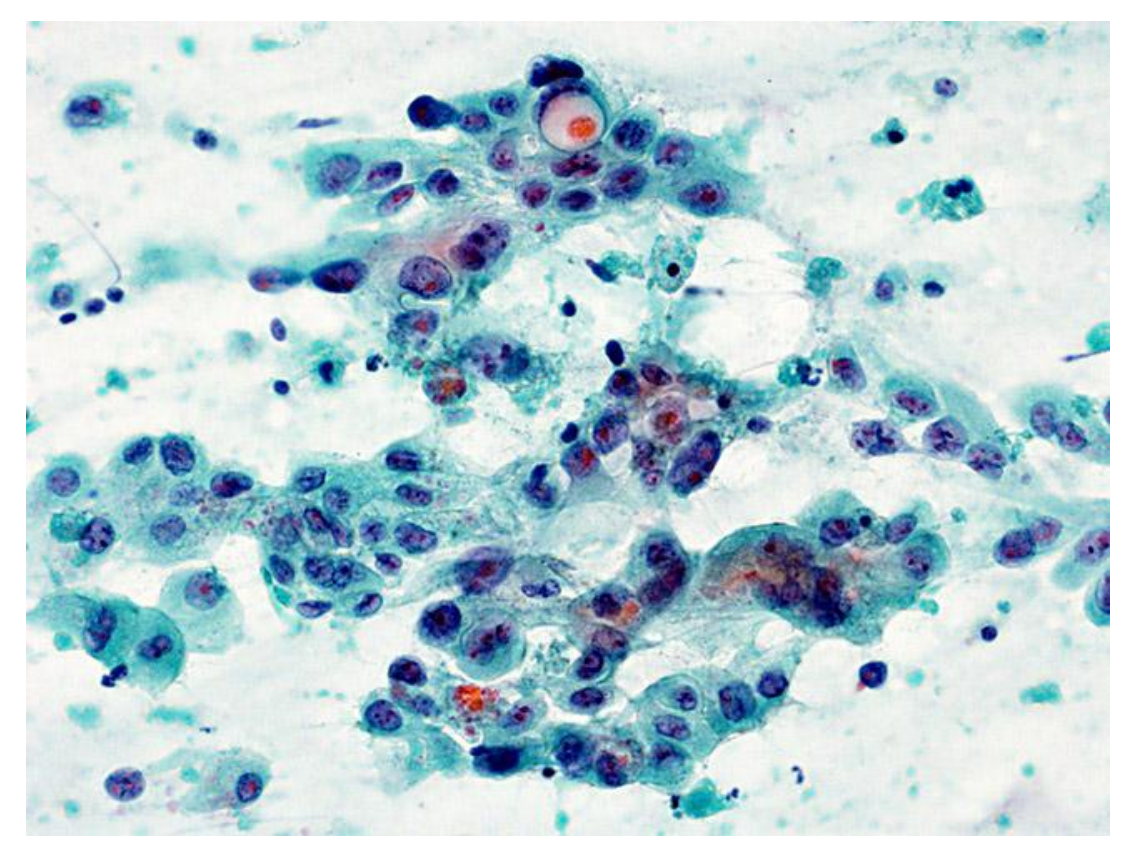

Fig. 2. Pathological findings (40× objective lens, Papanicolaou stain) showed cells in an arranged pattern or irregular overlapping. The nuclei varied markedly in size. The N/C ratio was increased. Nuclear atypicality was observed while nuclear bodies were distinct.
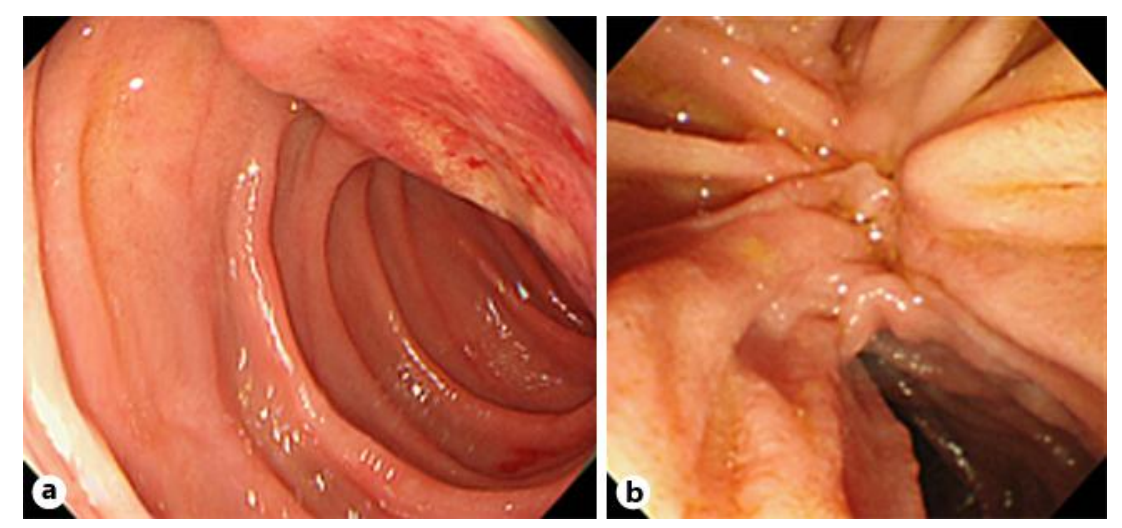

Fig. 3. a Upper gastrointestinal endoscopic findings on the first episode of melena showed an enormous and deep ulcer in the second portion of the duodenum caused by direct infiltration of pancreatic cancer. b One month after discharge the examination was performed again. The enormous ulcer base was markedly reduced in size. 